\title{
Política de educação continuada institucional: um desafio em construção
}

\section{I nstitutional police of continued education: a challenge in construction}

\author{
Politica de la educación continuada institucional: un desafío en construcción
}

\author{
Elisabeta Albertina Nietsche', Vânia Marli Schubert Backes 'I, Fabiane Ferraz 'I', Luciana Loureiro'IV,
} Sandra Marcia Soares Schmidt ${ }^{\mathrm{V}}$, Helena Carolina Noal ${ }^{\mathrm{VI}}$

\begin{abstract}
1 Pesquisa financiada pelo PIBIC/CNPq/UFSM, desenvolvida pelo Grupo de Estudos e Pesquisas em Saúde e Enfermagem da Universidade Federal de Santa Maria (GEPES/UFSM). Artigo construído a partir da pesquisa intitulada "A Educação Continuada no trabalho: possibilidades para a construção de uma práxis institucional transformadora".

Dra. em Enfermagem. Profa. Associado do Departamento de Enfermagem da UFSM. Coordenadora do GEPES/UFSM e Membro do Grupo de Pesquisa em Educação em Enfermagem e Saúde da Universidade Federal de Santa Catarina (EDEN/UFSC). Email: enietsch@terra.com.br.

"Dra. em Enfermagem. Profa. Associado do Depto. de Enfermagem da UFSC. Coordenadora do EDEN/UFSC e Membro do GEPES/UFSM.

Diretora de Educação da ABEn-SC- Gestão 2005-2007. Pesquisadora CNPq. Email: oivania@nfr.ufsc.br.

III Enfermeira. Mestre em Enfermagem. Doutoranda do Programa de Pós-Graduação em Enfermagem da UFSC (PEN/UFSC). Bolsista CNPq/PEN/UFSC. Membro do EDEN/PEN/UFSC e GEPES/UFSM. Email: olaferraz@yahoo.com.br.

VI Enfermeira do Hospice San Martino de Como-Lombardia (Itália). Membro do Grupo de Pesquisa GEPES/UFSM e EDEN/PEN/UFSC. Email: luloureiro23@hotmail.com.

$\checkmark$ Msc. em Educação pelo Programa de Pós-Graduação em Educação - PPGE/UFSM. Doutoranda do PEN/UFSC. Enfermeira do Hospital Universitário de Santa Maria (HUSM/UFSM). Membro do GEPES/UFSM e EDEN/UFSC. Email: sandra@smail.ufsm.br.

VI Enfermeira do HUSM/UFSM. Mestranda do Programa de Pós-Graduação em Enfermagem da UFSM. Membro do GEPES/UFSM. Email: hcn2@pop.com.br.
\end{abstract}

\section{RESUMO}

Esta investigação de natureza qualitativa teve por objetivo descrever e analisar o exercício do processo de construção de uma Política de Educação Continuada Institucional de um Hospital Universitário da região sul do Brasil. A pesquisa envolveu membros da diretoria, coordenadores dos serviços e participantes dos programas de Educação Continuada das áreas administrativa, médica e de Enfermagem. A coleta de dados foi realizada pela técnica de Grupo Focal, mediatizada pela metodologia problematizadora desenvolvida no período de março a julho de 2005. Como problemas destacaram-se: deficiência de comunicação e de relacionamento interpessoal e despreparo dos profissionais para gerenciar. Nas conclusões, foi manifestado pelos sujeitos como necessidades para a construção de uma política de Educação Continuada Institucional: interação entre as três áreas e o envolvimento da diretoria geral; fortalecimento de parcerias entre os departamentos de ensino e o hospital Universitário; de considerar a Educação Continuada como inerente ao trabalho, dispondo de carga horária própria. A criação de comissões foi referida como uma estratégia para a operacionalização destas ações.

Descritores: Política Organizacional; Educação Continuada; Enfermagem.

\section{ABSTRACT}

This paper resultant of the inquiry has as an objective to describe and analyze the exercise of the construction process of a Political Institutional Continued Education in the University Hospital of the south region of Brazil. It was a qualitative research, which involved direction members, services coordinators and participants of the continued education programs of the administrative, medical and nursing fields. The data collection was achieved by the focal group technique, through the problem methodology developed in the period March-July of 2005. As problems were distinguished: communication deficiency, interpersonal relationship and the un-preparedness of the professionals for the management. In conclusion it was revealed, as necessities for the construction of an institutional continued education policy: the importance of interaction among the three areas and the involvement of the general direction; to supply partnerships among the education departments and the University Hospital; and to consider the continued education as inherent to work, making use of the job schedule for such. The creation of commissions was related as a strategy to operate these actions.

Descriptors: Organizational Policy; Continued Education; Nursing.

\section{RESUMEN}

El presente trabajo es el resultado de una investigación cualitativa, cuyo objetivo fue describir y analizar el ejercicio del proceso de construcción de un Proyecto Político de Educación Continuada Institucional, en un Hospital Universitario de la región sur del Brasil. La investigación fue realizada con los miembros de la dirección, los coordinadores de los servicios y los participantes de los programas de Educación Continuada de las áreas administrativa, médica y de enfermería. La recolección de los datos se hizo por medio de la técnica de grupo focal, utilizando la metodología problematizadora desarrolhado en el período comprendido entre marzo-julio de 2005. En la investigación se destacaron los siguientes problemas: deficiencia en la comunicación y en la relación interpersonal, así como falta de preparación de los profesionales para ejercer la gerencia. En las conclusiones fueron señaladas como necesidades para la construcción de una política de educación continuada institucional: la importancia de la interacción entre las tres áreas y una mayor participación de la dirección general; el fortalecimiento de las asociaciones entre los departamentos de educación y el Hospital Universitario; considerar la educación continuada como inherente al trabajo, disponiendo de carga horaria para esa actividad. La creación de comisiones fue señalada como una estrategia necesaria para la ejecución de estas acciones.

Descriptores: Política Organizacional; Educación Continuada; Enfermería. 


\section{NTRODUÇÃO}

A

indissociabilidade

entre

Ensino/Pesquisa/Extensão (EPE) no contexto das universidades não é propriamente uma novidade, entretanto, essa tríade merece atenção face às aceleradas mudanças científico-tecnológicas e político-sociais da atualidade. Observa-se, com muita freqüência, uma predominância da função de ensino sobre as demais, acarretando uma secundarização da pesquisa e da extensão, em particular no ensino privado. Essa centralidade da reprodução do conhecimento sobre a sua produção e apresentação de serviços à comunidade torna, entre outros aspectos, limitado o próprio exercício da função de ensino, ocasionando o desenvolvimento de pesquisas desvinculadas do seu principal "locus" - os serviços, e tão pouco a extensão intervém na sociedade ${ }^{(1)}$.

Acredita-se que o horizonte para a indissociabilidade do EPE pode ser expresso como uma ação vinculada, contínua e processual de uma nova política, uma nova postura, fomentando a parceria docência-serviço numa disposição para ultrapassar os limites da Universidade. Isso certamente propicia um fluxo de troca de saberes sistematizados, favorecendo um trabalho interdisciplinar e, igualmente, fornecendo elementos para interpretação e transformação da realidade de saúde.

Neste sentido, para atender a esta necessidade de fortalecimento na articulação equânime EPE, é fundamental estabelecer um modelo de capacitação que promova a atenção integral à saúde, alicerçado na aprendizagem significativa: a Educação Permanente em Saúde(2). É importante esclarecer que na perspectiva de transformação, é preciso pensar em um trabalho que supere a dicotomia do pensar/fazer, que seja ampliada e que favoreça a formação ao longo da vida do profissional, seja ela intitulada de Educação Continuada ou Educação Permanente ${ }^{(3)}$.

No Brasil, considerando as decisões da reunião da Comissão Intergestores Tripartite - CIT e a criação da Política Nacional de Educação Permanente em Saúde, ficou estabelecido que esta Política deva ser conduzida com a participação das Comissões Permanentes de Integração Ensino-Serviço (CIES). Estas participam da formulação, condução e desenvolvimento das ações de ensino em serviço, considerando as especificidades regionais para a superação de desigualdades, necessidades de formação e desenvolvimento para o trabalho em saúde e a capacidade já instalada de oferta institucional de ações formais de educação na saúde ${ }^{(4)}$

Essa disposição de integração, de parceria e de mudança, mais do que no plano do conhecimento, situa-se na práxis. Uma práxis que tenha disposição para produzir conhecimento histórico inovador, voltado para a realidade de saúde da região e que seja objeto do ensino e suporte da prestação de serviços à comunidade ${ }^{(1)}$. Desse modo, acredita-se que para assumir essa disposição seja necessário ocorrer uma articulação da Universidade com os profissionais egressos inseridos no mercado de trabalho, aproximando e fortalecendo a tríade do Ensino/Pesquisa/Extensão, por meio da construção de uma política de Educação Continuada institucional.

$\mathrm{Na}$ área da saúde e mais especificamente da Enfermagem, a Educação Continuada, é preocupação mundial contribuindo para a transformação da práxis dos (as) trabalhadores (as) de Enfermagem, pois provocam debates e propostas acerca do movimento rico em possibilidades de melhorar a qualidade dos serviços e de desenvolvimento pessoal e institucional.

O conceito de Educação Continuada, embora seja um conceito antigo ${ }^{(3)}$, somente na atualidade tem sofrido as reformulações compatíveis com seu real valor na sociedade moderna e pós-moderna. Se antigamente a Educação Continuada estava atrelada a um mero processo de aperfeiçoamento técnicoprofissional; atualmente já vem sendo entendida como um processo mais amplo.

Assim, o conceito que se utiliza no contexto deste trabalho é de que a Educação Continuada é um processo educativo formal ou informal, dinâmico, dialógico e contínuo, de revitalização pessoal e profissional, de modo individual e coletivo, buscando qualificação, postura ética, exercício da cidadania, conscientização, reafirmação ou reformulação de valores, construindo relações integradoras entre os sujeitos envolvidos, para uma práxis crítica e criadora $^{(5)}$.

Esta forma abrangente de entender o processo de Educação Continuada acredita-se, vir ao encontro dos anseios da sociedade, que vive a era da globalização e da revolução tecnológica, atrelada a graves problemas de ordem social e econômica. Sob esta ótica, a Educação Continuada não pode estar relacionada somente com o aperfeiçoamento técnico, mas também com uma constante reflexão de valores, dentro de um contexto coletivo.

Esta tipologia de educação é caracterizada como um momento histórico, pela incessante busca e renovação do saber-fazer educativo, criando novas possibilidades na renovação e inovação da realidade pessoal e profissional da Enfermagem numa prática dialógica entre o individual e coletivo, ou seja, entende-se a Educação Continuada, como uma das provedoras do conhecimento da ação (saber-fazer), e da reflexão (pensar sobre o fazer), para que mediante o processo de "aprender a pensar o fazer" culmine no "refazer" as ações realizadas no cotidiano $^{(6)}$.

É percebido, atualmente, interesse das instituições em aderir à Política de Educação 
Continuada, com a intenção de qualificar seus profissionais. Esta finalidade contempla vários obstáculos tanto no âmbito de construção, como no de implementação desta Política, visto que, muitas vezes, ocorre uma resistência dos próprios profissionais da saúde. Trata-se de um processo lento, porém gradual, pois se necessita a priori da disponibilidade dos trabalhadores para o diálogo e para as necessidades das pessoas, visto que a Educação Continuada como uma transformação político-social deve partir da compreensão da realidade dos profissionais enquanto construtores da história, seres de decisão, da ruptura, da opção e da ética ${ }^{(7)}$.

Para que a Educação Continuada no trabalho se torne efetiva, deve-se crer que a educação seja de grande valor como meio de crescimento dos trabalhadores da saúde, o que contribuirá para a melhoria da assistência aos sujeitos-cidadãos do cuidado $^{(8)}$. Esse desenvolvimento dos trabalhadores de Enfermagem, por exemplo, está atrelado à existência de um setor que planeje e organize as atividades de Educação Continuada ${ }^{(9)}$. Isto assegura que o desenvolvimento dos trabalhadores seja uma prática institucional, portanto, com maiores chances de sucesso.

Em concordância, apresenta-se a perspectiva do desenvolvimento profissional como um processo dinâmico e flexível, que deveria ser parte integrante de toda carreira do Enfermeiro(10), bem como, dos demais trabalhadores da equipe de Enfermagem. É inegável o benefício direto que este processo de aperfeiçoamento pode trazer ao sujeito-cidadão do cuidado e seus familiares e, indiretamente, para toda equipe de saúde e a instituição.

Sabe-se que, a Educação Continuada no trabalho, proporcionada por meio da parceria docência-serviço, precisa levar em consideração o saber adquirido pelo profissional nas experiências de trabalho. A valorização desse saber permite, apontar com maior propriedade a realidade desse serviço, a expressão de suas necessidades e problemas, estimulando no processo de Educação Continuada a troca mútua de experiências, a criação de novo saber e nova prática, a partir da crítica e instrumentalização gerada pela vivência deste processo $^{(11)}$.

Neste sentido, a Política de Educação Continuada Institucional considera que, a perspectiva de educação está relacionada a conhecimentos e saberes que se aliam no exercício profissional, tornando-se necessário gestar uma política pública de educação contínua, vista esta ter início definido, mas não ter fim $^{(12)}$. Portanto, deve ser concebida no contexto de uma política global para a organização e gestão do trabalho, "não como suplência de carências", nem como treinamento para novas tarefas, mas como um direito concomitante ao direito ao trabalho.

No âmbito Institucional, por sua vez, o desenvolvimento de Educação Continuada, tem demonstrado uma preocupação maior com relação ao acompanhamento do avanço tecnológico de equipamentos proporcionando tão somente a denominada educação em serviço, cujo foco é o treinamento e aperfeiçoamento do trabalhador. Ainda, a realidade nesta área tem mostrado que as iniciativas são isoladas e levadas a efeito de diferentes maneiras dentro da mesma instituição criando muitas vezes barreiras e dificuldades de entendimento nas relações de trabalho e na própria organização dos setores na Instituição(13).

Desta forma, é defendida aqui, a construção de uma Política de Educação Continuada Institucional, na qual se evidencia a participação de todos os segmentos ou áreas (administrativa, Enfermagem, médica, de apoio, entre outras), na formulação do mesmo. Em torno desse deve-se ter como objetivo a conjugação de esforços em torno de propósitos comuns que privilegiem uma excelência na prestação de serviços à comunidade, bem como na melhoria das condições de trabalho gerando satisfação e motivação para o trabalhador. Nota-se que à medida que a referida Política apresenta seus marcos referenciais, os quais explicitam a rede de articulação e interdependências, há equanimidade de responsabilidades e importância produzindo melhor aderência das pessoas envolvidas e maior grau de compromisso para o êxito e correspondência de ações e de resultados.

Assim, este estudo considerou dois pressupostos: primeiro, a necessidade de despertar o compromisso da Universidade no campo da docência quanto ao processo de Educação/Formação Continuada no trabalho dos profissionais egressos dos Cursos de Enfermagem e, segundo, a realidade da Educação Continuada nos serviços de saúde mostrar-se frágil e pouco efetiva, demonstrando a relevância da construção de parcerias entre Docência/Cursos de Enfermagem/Grupos de Pesquisa e os Profissionais Egressos/Serviços de Saúde, no intuito de viabilizar estratégias que assegurem transformações dos serviços de saúde e retroalimentação da formação profissional inicial. Desse modo, o presente estudo teve por objetivo, descrever e analisar o exercício do processo de construção de uma Política de Educação Continuada Institucional em um Hospital Universitário da Região Sul do Brasil.

\section{PERCURSO METODOLÓGI CO}

O estudo foi desenvolvido em um Hospital Universitário da Região Sul do Brasil, no período de março a julho de 2005, configurando-se como uma investigação qualitativa, de natureza convergente- 
assistencial, a qual sempre requer participação ativa dos sujeitos envolvidos na investigação, e, está orientada para a resolução de problemas na prática ou para a realização de mudanças na área de atuação, o que poderá resultar em uma construção teórica(14), neste caso a construção de uma Política de Educação Continuada Institucional. Para tanto, este tipo de pesquisa é compreendida e realizada, em articulação com as ações que envolvem pesquisadores e demais pessoas representativas da situação a ser pesquisada, numa relação de cooperação mútua.

A investigação foi desenvolvida com membros da Diretoria Executiva (DIREX), Coordenadores dos Serviços de Educação Continuada (CSEC) das áreas administrativa, médica e de Enfermagem e com participantes de Programas de Educação Continuada (PPEC), de um Hospital Universitário, por meio da técnica do Grupo Focal e mediatizada pela metodologia problematizadora.

O Grupo Focal é uma estratégia metodológica qualitativa não-diretiva, que utiliza sessões grupais nas quais os participantes emitem diferentes opiniões em relação ao tema discutido, num diálogo aberto e coerente com os objetivos propostos. Nesse contexto existe liberdade em comentar, perguntar e responder os comentários dos próprios participantes e do moderador. O método permite a coleta de dados diretamente das falas de um grupo, que relata suas experiências e percepções em torno de um tema de interesse coletivo. Esta técnica de coleta de dados consiste, portanto, em "buscar informações não de um indivíduo, mas em um grupo já existente ou formado especificamente para um período destinado à coleta de dados, que se reúna em torno de um interesse relacionado ao tema de investigação"(15).

$\mathrm{O}$ estudo foi desenvolvido em dois momentos, sendo o primeiro a sensibilização, etapa que consistiu no contato inicial com os sujeitos apresentando o convite para participar do estudo. Nesse momento, estes eram chamados a atenção para a importância de sua participação na investigação, informando igualmente os propósitos da mesma, bem como solicitando sua carta de aceite, por meio do Consentimento Livre e Esclarecido, conforme Resolução CNS no 196/96 e aprovação do Comitê de Ética em Pesquisa com Seres Humanos, com o Processo no 108/01.

No segundo momento, denominado sistematização e avaliação da construção de Política de Educação Continuada Institucional, os sujeitos definidos variaram entre 08 (oito) e 14 (quatorze) participantes no decorrer dos 07 (sete) encontros. Foram realizadas várias etapas, dentre as quais destacam-se :

- Definição do Tema: foram especificados os objetivos da investigação e a temática a ser desenvolvida e, de que os resultados a serem construídos poderiam expressar-se em ações apropriadas para o planejamento e tomada de decisões. Ao mesmo tempo, foi discutido o modo de desenvolvimento dos encontros baseados na Metodologia Problematizadora;

- Seleção do Moderador e o(s) Observadore(s) do Grupo Focal: o papel do moderador consiste em intermediar, questionar os membros do grupo, auxiliando no esclarecimento de possíveis respostas. Ao(s) observadore(s), coube auxiliar o moderador no sentido de perceberem as atitudes, preocupações, linguagem, dentre outros aspectos dos integrantes do grupo. As orientadoras do estudo atuaram como as moderadoras (duas) e as bolsistas da pesquisa foram observadoras (duas);

- Desenvolvimento dos Encontros: os encontros foram dinamizados levando-se em consideração a passagem por três grandes momentos, adequando-os a Metodologia Problematizadora, sendo eles: - Momento de Diagnóstico da Realidade e Levantamento dos Problemas-Chave; - Momento de Teorização e Levantamento de Hipóteses; e - Momento da Construção Coletiva de Política de Educação Continuada Institucional - um passo para a implementação.

A análise dos dados foi realizada mediante a análise temática ${ }^{(16)}$, logo após a coleta dos dados, e validada a cada encontro desenvolvido em conjunto com os participantes, referendando os resultados obtidos.

\section{RESULTADOS E DI SCUSSÃO}

Por meio de narrativa focalizada na seqüência dos encontros, buscou-se fornecer uma noção de conjunto, quanto ao movimento do grupo. Salientase que no primeiro momento, houve a apresentação pessoal dos componentes do grupo e a apresentação do Projeto de Pesquisa pelas moderadoras, enfocando os propósitos do mesmo e as vantagens que existem no desenvolvimento de projetos desta natureza, ressaltando a necessidade de haver o real envolvimento e comprometimento dos sujeitos para que se alcancem resultados positivos.

No decorrer dos encontros o grupo se mostrou interessado, sendo que os componentes questionaram sobre a relação deste trabalho com outras iniciativas de Educação Continuada em serviço e manifestaram apoio sobre a tentativa de criação de uma Política de Educação Continuada Institucional, 
por meio de um grupo focal como esse, relatando que:

Desta forma podemos trazer nossa realidade e a partir daí ocorrer interação, pois não se pode ter a idéia de que se resolverá tudo do dia para a noite, mas de alguma maneira temos que começar. (Adm. 1)

Essa consideração reforça a idéia de que a Educação Continuada/Permanente em serviço é de extrema significância e que está na sua dependência o avanço da profissão Enfermagem. Para superar as novas tendências do mercado de trabalho e manter os profissionais da saúde em constante atualização, com reforços aos aspectos críticos e criativos, levando em conta as demandas sociais e os desafios impostos pela globalização, é necessário manter os profissionais da saúde em constante processo educativo em seu ambiente de trabalho ${ }^{(11-12,17)}$.

Quando foi solicitado que os componentes do grupo realizassem uma atividade de forma a atender a "captação da realidade" - primeiro momento da metodologia problematizadora - sobre o que para os mesmos seria uma Política de Educação Continuada Institucional $(\mathrm{PECl})$, houve as seguintes exposições verbais:

Para nós deveria haver uma $\mathrm{PECl}$ com base na missão e visão da nossa instituição. (Enf.2)

Seria uma Educação Continuada que contemplasse todos os setores - Enfermagem, médico, administrativo, docentes, entre outros, com o envolvimento da direção geral dessa instituição, objetivando um serviço de qualidade. (Adm.1)

A necessidade da gerência se envolver ou ter uma política, mas não se trata apenas de um cronograma, mas alguma coisa a mais para a instituição em cima disso trabalhar envolvendo todos os trabalhadores. Os departamentos também seriam envolvidos, pois como nós somos um hospital escola, nós precisamos do envolvimento dos departamentos que atuam aqui dentro. (Enf.3)

Uma Política de Educação Continuada Institucional deve ser uma construção coletiva, junto com a direção, coordenações e chefias. Teria que se construir um plano de ação juntamente com a direção e os serviços que tenham influência direta ou indireta nas questões que forem propostas. E aí é fundamental conhecer as diretrizes da direção para que se busque a fundamentação do que se pretende realizar. (Adm.2)

É fundamental não só a participação da direção, mas o envolvimento dela nas questões. (Adm.1)

Notou-se que a apresentação dessas idéias contempla a exposição da idealização do grupo e não a realidade que se encontram. Contudo, as idéias vão ao encontro de uma realidade desejada. "As mudanças de concepções e práticas de saúde dependem da ruptura com a alienação do trabalho, do resgate da possibilidade de produzir conhecimento a partir das práticas e da democratização da gestão e dos processos de trabalho"(2).

Chamou atenção a exposição gráfica das idéias realizadas pelo grupo, para a qual foi utilizada a forma de círculos, pois dessa maneira, acredita-se que se conseguiu explicitar a importância de horizontalizar as relações, uma vez que todos os membros das diferentes áreas se encontrariam num mesmo nível, com um mesmo intuito, por mais que haja uma certa tendência de verticalização histórica por parte das equipes diretivas.

Percebeu-se uma convergência de idéias, no tocante, a ser um projeto coletivo levando em consideração as bases, a filosofia da instituição, bem como envolver/comprometer a direção para que de fato se efetive, ou melhor, conte com o respaldo da diretoria. Também ficou implícito que a discussão de construção de uma Política, passa pela necessidade, de que esta seja coletiva, destacando-se a participação da academia nessa questão(13).

Num outro momento, a discussão recaiu no tema da carga horária de trabalho e da necessidade de se incorporar o estudo no processo de Educação Continuada. Porém, surgiram questionamentos no grupo, como: Mas como gerenciar estas questões se vai faltar pessoal para a assistência? Como promover capacitação em serviço no horário de trabalho, e de forma que todos participem, e não sempre as mesmas pessoas?

Prever horas de aprendizado dentro da carga horária é um exemplo de política, num processo de Educação Continuada que respaldaria as negociações neste sentido. Experiências de êxito, como a dos hospitais da Rede Sarah, indicam que o processo educativo contínuo, bem como o desenvolvimento de pesquisas, pode acontecer em instituições que asseguram serviços públicos de saúde com qualidade e que, inclusive, o programa de treinamento de profissionais consta como exigência no contrato de gestão. Nestas instituições, os profissionais da saúde têm dedicação exclusiva ao serviço e o processo de Educação Continuada é formal, incorporado na carga horária de trabalho, o que atribui créditos à instituição, qualidade de atendimento aos usuários e crescimento pessoal/profissional dos trabalhadores da saúde ${ }^{(18)}$.

Com relação à capacitação em horário de trabalho, os sujeitos expressaram:

Nós deveríamos ter um calendário com propostas de atividades para todos os setores e com respaldo da direção, com cobrança, com seriedade... (Enf.4)

Outro participante lembrou:

Só para não esquecer, que nós trabalhamos em um hospital de serviço público, de forma que se as coisas não forem postas dentro do horário do trabalho, elas não funcionam. (Enf.1) 
Outros colegas complementam:

A pessoa tem que entender o estudo como trabalho para, então, participar. (Enf.2)

Sim, porque se tiver que ficar fora da tua carga horária para reuniões e estudo, ninguém fica. Esta é a realidade. (Enf. 1)

Há diversos fatores que podem prejudicar a participação dos trabalhadores da saúde nos processos educativos em serviço. São incluídos a "falta de estímulo financeiro, falta de um plano de cargos e salários, a longa duração, dias inadequados, necessidade de custear o transporte, a ocorrência de cursos fora do horário de expediente e a deficiente infra-estrutura, que envolve a falta de organização e as condições do local da capacitação"(2).

Muitos trabalhadores, ainda, não participam dos processos educativos por falta de metodologia adequada, com predomínio da metodologia expositiva $^{(2)}$. Esta metodologia é enquadrada no modelo de acomodação, de ensinar as pessoas a se adaptar e aceitar todas as situações sociais tais como elas se mostram cujo enfoque é autoritário. Os alunos são passivos e o sentido do fluxo do conhecimento é mão única ${ }^{(7,17)}$.

Conforme indica Freire ${ }^{(7)}$ a educação não pode ser um processo de adaptação dos indivíduos à sociedade, mas um mecanismo que busca a transformação desta realidade, em cujas relações são reflexivas, conseqüentes, transcendentes e temporais.

A adoção desta metodologia expositiva é contrária às propostas iniciais da Educação Continuada/Permanente, que visa construir um processo educativo que atribua mudanças às práticas antigas, arraigadas na repetição. É importante que, além de instalado um processo contínuo de ensino em serviço, este disponha de estruturas que fortaleçam a participação crítica, a inclusão e permanência dos trabalhadores neste processo, que permita que os sujeitos respondam aos desafios do mundo a partir de metodologias pedagógicas ativas.

Das tendências pedagógicas existente, é fato que a prática educativa norteada pela pedagogia da problematização é a mais adequada à pratica educativa em saúde. Esta prática visa promover a valorização do saber dos profissionais, instrumentalizando-o para a transformação de sua realidade e de si mesmo de forma crítico-criativa, possibilitando efetivação do direito da clientela às informações de forma a estabelecer sua participação ativa nas ações de saúde ${ }^{(7,12,17,19)}$.

As discussões, ainda se voltaram para este aspecto com diversos exemplos e a moderadora, assim se manifestou:

A discussão está muita boa. Mas, nota-se dois aspectos que é aquela situação-problema do cotidiano, de quem vai e faz o curso, por exemplo; e tem a questão maior, macro, que é o poder de decisão de estratégias e de políticas de incorporar como um todo pela instituição, e nesse respeito, uma delas é a questão de carga horária. (Mod.1)

Frente aos aspectos elucidados, a operacionalização da política também foi motivo de debate, aparecendo algumas estratégias como a utilização de comissões e sub-comissões, e uma espécie de conselho subsidiando as decisões, compartilhando melhor as iniciativas e o poder decisório.

Esta lógica vem ao encontro da proposta de trabalho em equipe matricial em saúde e corresponde às idéias de Campos $^{(20)}$, quando destaca que esta “objetiva assegurar retaguarda especializada a equipes e profissionais encarregados da atenção a problemas de saúde". Neste sentido, a criação do apoio matricial visa oferecer tanto retaguarda assistencial quanto suporte técnico-pedagógico às equipes de referência. “Depende da construção compartilhada de diretrizes clínicas e sanitárias entre os componentes de uma equipe de referência e os especialistas que oferecem apoio matricial."

Em outro encontro, o ponto forte recaiu sobre a necessidade de se integrar às atividades de Educação Continuada, de se sistematizar e planejar conjuntamente essas iniciativas, uma vez que da forma como vem sendo desenvolvida é extremamente desgastante; pois muitas vezes, só há o coordenador da Educação Continuada, não há uma infra-estrutura nestes setores, nem ao menos alguém que realize o trabalho básico: de digitação de materiais e avisos, de reserva de sala, de checagem de material áudio-visual e equipamentos que serão usados em um encontro ou evento. Alguns participantes do estudo comentaram que as pessoas não fazem idéia do estresse que é organizar um evento, uma palestra, e devido a isso, não apóiam quando é solicitado um secretário específico para este setor.

Analisando as discussões, ficou evidente que a Educação Continuada promove maior qualificação profissional e por sua vez maior qualidade da assistência e, deste modo, prescinde de uma política organizacional que seja multidisciplinar, isto é, que se possa trabalhar todas as áreas integradas, e não, de maneira isolada e fragmentada como vem ocorrendo.

Outro tópico abordado foi referente, as diferentes iniciativas, que vem ocorrendo e que não são conhecidas por todos, que não são muitas vezes registradas. Comentou-se, brevemente, sobre o Projeto de Humanização e de um Curso de Gerenciamento que está sendo desenvolvido pelo Departamento de Enfermagem e Coordenação de Educação Continuada de Enfermagem do Hospital Universitário, para Enfermeiros. 
Problemas como a deficiência de comunicação, de relacionamento interpessoal e o despreparo para o gerenciamento, também foram alvo de discussões. Neste sentido, vale ressaltar que o entendimento sobre o processo educativo não pode ser reduzido a um aspecto puramente quantitativo, em aumentar a quantidade de educação, mas sim, utilizar metodologias que possibilitem um maior desenvolvimento dos trabalhadores da saúde, com estabelecimento de relação horizontal na díade gerência e equipe, para um despertar crítico, voltando para a realidade dos serviços, com o intuito de concretizar mudanças ${ }^{(12)}$.

Ainda, deve ser um processo que parte da necessidade dos trabalhadores e dos serviços e construído coletivamente, visto que se for imposto de forma verticalizada pelas direções dos serviços, o processo de Educação Continuada Institucional pode não refletir a alavanca na transformação social, mas ao invés disso, insinuar necessidades e objetivos que não refletem a realidade dos serviços e o interesse dos trabalhadores e, conseqüentemente, pode não despertar reflexos nas ações de saúde ${ }^{(13)}$.

Finalizando o tempo dos encontros, as moderadoras assim se manifestaram:

Mudanças são difíceis, devido a isso, as mudanças devem ser construídas e não impostas e, mais, o que devemos pensar é de que forma se pode desenvolver o processo de construção? Então pessoal, vamos articular toda a questão de relacionamento humano, de gestão de pessoal, vamos unir forças das três áreas? Como? Para que? Vamos estudar o que? Devemos investir na ponta que se tem mais força, e digamos que esta força é na área de psicologia, do repouso e do trabalho, é aí que deve se investir. Vamos planejar algo bem interessante, forte. (Mod.1)

Neste sentido, habitualmente é percebido um "crescente interesse institucional na educação continuada com o intuito de melhoria da capacitação técnica dos seus profissionais", visto que este processo contribuiu para a realização de ações integradas, maior qualidade nas práticas e benefícios à instituição. Contudo, o processo educativo continuo, por si só, é “insuficiente para que seja de fato compreendido como importante em primeira instância pelos próprios profissionais", sendo necessário, ainda, um despertar crítico destes trabalhadores, um desvelamento da educação em serviço $^{(13)}$.

No penúltimo encontro, concluiu-se que há várias propostas que perfeitamente poderiam otimizar esforços se fossem desenvolvidas em parceria ou de forma integrada, sendo registrado o comentário de um participante, a respeito da avaliação do processo:

Estes encontros foram importantes, porque é o primeiro impacto, mas já conseguiu aglutinar e motivar, visto que agora as áreas da administração e da Enfermagem estão buscando formular ações integradas. (Adm.2)

Uma pesquisa desenvolvida em Florianópolis ${ }^{(13)}$, capital do estado de Santa Catarina (Brasil), em que foi verificado o processo de Educação Continuada/Permanente na Saúde Pública deste município, tendo como sujeitos não só trabalhadores da saúde, mas também, dirigentes das instituições e da Secretaria Municipal e Estadual de Saúde, corroboram com esta realidade. Os resultados desta pesquisa indicaram que a realidade da educação continuada está "encaminhando-se para uma política institucional mais integrada, apesar de não ser plenamente referido pelos sujeitos de algumas instituições." Este descompasso é presente nos processos de estruturação e/ou planejamento de propostas dos diferentes níveis. "Acredita-se que, para haver maior integração, um passo imprescindível seja tornar mais visíveis as ações empreendidas no âmbito central".

Outra fala destacou a importância do trabalho coletivo e de se fortalecer a parceria com os docentes/academia em geral, de todas as áreas. Ainda, as manifestações dos sujeitos acenaram sobre a importância da integração, especialmente, da Enfermagem, da área administrativa e da Coordenação de Recursos Humanos, efetivada por meio dos nossos encontros, contribuindo para que houvesse mais diálogo, mais abertura para questionamentos e união.

\section{CONSI DERAÇÕES FI NAIS}

Por muito tempo, falar de Educação Continuada em Enfermagem sugeriu a idéia de um ensino de técnicas, realizado em um determinado setor de uma instituição. Hoje, porém, deve-se compreender que o processo de Educação Continuada é muito mais amplo e abrangente, devendo estar presente a todo o momento e ser de livre acesso, a todos os que julgarem necessário a busca constante de construção de conhecimentos.

Uma Política de Educação Continuada Institucional, parte do pressuposto de que os setores ou serviços de uma Instituição são intercomplementares, que os diferentes profissionais técnicos administrativos e de apoio podem exercitar o trabalho interdisciplinar e, que ao construírem coletivamente uma Política de Educação Continuada, poderão formalizá-lo e comprometerem-se com o mesmo retroalimentando suas ações e gerando as transformações necessárias para melhores qualidade nos serviços prestados à saúde da população.

Com essa visão, é que por meio de um grupo focal de sujeitos de um Hospital Universitário da Região Sul do Brasil, elencou-se entre os problemas da instituição: a deficiência de comunicação, de relacionamento interpessoal e o despreparo para o 
gerenciamento. Sobre as necessidades da construção de uma Política de Educação Continuada Institucional, o grupo manifestou: a importância de integração entre as áreas administrativa, Enfermagem e médica, bem como o envolvimento da diretoria geral da instituição. A composição e organização de um calendário com atividades comuns e de interesse coletivo foi outro ponto forte nas discussões.

Frente às situações expostas, faz-se necessário que seja instituída nos serviços de saúde uma Política de Educação Continuada/Permanente, a fim de suprir essas lacunas e também fazer parte do processo de trabalho dos profissionais de saúde, em que a reflexão e a atualização de sua práticas seja feita no seu cotidiano.

Ainda, os sujeitos ressaltaram a importância e necessidade do trabalho multidisciplinar, o fortalecimento da parceria com a academia/departamentos de ensino e o Hospital Universitário, e a consideração do aprendizado/estudo como inerente ao trabalho e, por isso, desenvolvido no trabalho dispondo de carga horária para tal. A criação de comissões e/ou conselhos foi referida como uma estratégia para a operacionalização destas ações.

Portanto, é reafirmado aqui, que uma Política de Educação Continuada Institucional, visa articular diferentes áreas e interesses em torno de princípios e compromissos coletivos, criando avanços significativos na qualidade dos serviços prestados, em que todos se sintam integrantes e integrados aos propósitos institucionais.

\section{REFERÊNCI AS}

1. Reis RN. A institucionalização da extensão. Rev. Bras. Educ. 1992; 14(28):67-81.

2. Silva JAM, Ogata MN, Machado MLT. Capacitação dos trabalhadores de saúde na atenção básica: impactos e perspectivas. Rev. Eletr. Enf. [Internet]. 2007 [cited 2009 mar 09];9(2):389-401. Available from:

http:// www. fen.ufg.br/ revista/v9/n2/pdf/v9n2a08. pdf.

3. Backes VMS, Prado ML, Schmid SMS, Cartana MHF, Marcelino SR, Lino MM, et al. Educación continua o permanente de los profesionales de salud: el "nombre de la rosa" hace la diferencia? Revista Panamericana de Enfermería. 2005; 3(2): 125-31.

4. Ministério da Saúde; Conselho Nacional de Saúde. Portaria no 1.996, de 20 de agosto de 2007 - Dispõe sobre as diretrizes para implementação da Política Nacional de Educação Permanente em Saúde. Brasília (Brasil): Ministério da Saúde; 2007.

5. Backes VM, Nietsche EA, Camponogara S, Fraga RS, Cerezer RC. Continuing education of graduate students: a commitment of the university? Rev Bras Enferm. 2002; 55(2): 200-4.
6. Demo P. Educar pela pesquisa. Campinas: Autores Associados; 1996.

7. Freire P. Educação e mudança. 23nd ed. Rio de Janeiro: Paz e Terra; 1999.

8. Salum NC. Educação continuada no trabalho: uma perspectiva de transformação da prática e valorização do(a) trabalhador(a) de Enfermagem [dissertation]. Florianópolis: Centro de Ciências da Saúde/UFSC; 2000. 200 p.

9. Kurgant P. Administração em Enfermagem. São Paulo: EPU; 1992.

10. Oguisso T. A educação continuada como fator de mudanças: visão mundial. Revista Técnica de Enfermagem - Nursing. 2000;20(1):22-5.

11. Paschoal AS, Mantovani MF, Méier MJ. Percepção da educação permanente, continuada e em serviço para enfermeiros de um hospital de ensino. Rev. esc. enferm. USP. 2007;41(3):478-84.

12. Backes VMS, Schmidt SMS, Nietsche EA, Saurin MHG, Ferraz F. Educação Continuada: algumas considerações na história da educação e os reflexos na enfermagem. Texto contexto-enferm. 2003; 12(1): 80-8.

13. Lino MM, Backes VMS, Schmid SMS, Ferraz F, Prado ML, Martins ST. A realidade da Educação Continuada na Enfermagem nos Serviços Públicos de Saúde de Florianópolis. Online braz j nurs. [Internet]. 2007 [cited 2009 mar 09];6:0. Available from: http://www.uff. br/objnursing/index.php/nursing/artic le/view/619/147.

14. Trentini M, Paim L. Pesquisa em Enfermagem: uma modalidade convergente-assistencial. Florianópolis: Ed. UFSC; 1999.

15. Leopardi MT. Metodologia da pesquisa na saúde. Santa Maria: Pallotti; 2001.

16. Minayo MCS. O desafio do conhecimento: pesquisa qualitativa em saúde. São Paulo: Hucitec; 2004.

17. Reibnitz KS, Prado ML. Inovação e educação em enfermagem. Florianópolis: Cidade Futura; 2006.

18. Braga LW. Audiência Pública. Brasília: Câmara dos Deputados; 2005.

19. Pereira ALF. As tendências pedagógicas e a prática educativa nas ciências da saúde. Cad. Saúde Pública. 2003; 19: 1527-34.

20. Campos GWS, Domitti AC. Apoio matricial e equipe de referência: uma metodologia para gestão do trabalho interdisciplinar em saúde. Cad. Saúde Pública. 2007;23(2): 399-407.

Artigo recebido em 26.03.08.

Aprovado para publicação em 25.05.09. 